\title{
PENGARUH KEPUASAN KERJA TERHADAP KINERJA PEGAWAI DI BIDANG PROGRAM DAN PERENCANAAN UMUM BALAI BESAR WILAYAH SUNGAI MESUJI SEKAMPUNG DI BANDAR LAMPUNG
}

\author{
Ahiruddin ${ }^{(1)^{*}}$, Kuswarak ${ }^{(2)}$ Hujaimatul Fauziah \\ Fakultas Ekonomi Universitas Sang Bumi Ruwa Jurai \\ *email:ardhahabi123@gmail.com, kuswarak23@gmail.com,hujaimatul72@gmail.com
}

\begin{abstract}
Abstrak. Penelitian ini bertujuan untuk mengetahui pengaruh kepuasaan kerja terhadap kinerja pegawai di bidang program dan perencanaan umum balai besar wilayah sungai Mesuji sekampung di Bandar Lampung. Jenis penelitian yang digunakan dalam penelitian ini adalah kuantitatif deskriptif. Metode pengumpulan data yang digunakan data primer dan data skunder. Teknik pengumpulan data yang digunakan dalam penelitian ini observasi, wawancara, kusioner dan dokumentasi. Berdasarkan hasil penelitiam bahwa kepuasaan kerja berpengaruh terhadap kinerja pegawai di bidang program dan perencanaan umum balai besar wilayah sungai Mesuji sekampung di Bandar Lampung
\end{abstract}

Kata Kunci: Kepuasaan Kerja, Kinerja Pegawai

Abstract. This study aims to determine the effect of job satisfaction on employees in the field of program and general planning at the Balai Besar Mesuji River Sekampung in Bandar Lampung. The type of research used in this research is descriptive quantitative. Data collection method using primary data and secondary data. Data collection techniques used in this study were observation, interviews, questionnaires and documentation. Based on the research that job satisfaction has an effect on employee performance in the field of programs and general planning, the Mesuji River Basin Sekampung in Bandar Lampung

Keywords: Job Satisfaction, Employee Performance

\section{PENDAHULUAN}

Setiap orang tentu ingin mendapatkan kepuasan dalam melakukan setiap jenis pekerjaannya, karena kepuasan dalam bekerja dapat mempengaruhi kinerja yang dimiliki oleh seorang karyawan. Secara umum, kepuasan kerja dapat diartikan sebagai sikap dan perasaan senang atau tidaknya seorang karyawan dalam melaksanakan sebuah pekerjaan. Dewasa ini kepuasan kerja menjadi masalah yang penting dan sering dibicarakan, karena kepuasan kerja mempunyai pengaruh yang cukup besar terhadap kemajuan dan perkembangan suatu organisasi secara langsung maupun tidak langsung. Di samping itu kepuasan kerja terbukti banyak manfaatnya bagi individu, organisasi, perusahaan, dan masyarakat umum.

Bagi individu, penelitian tentang kepuasan kerja memungkinkan timbulnya usahausaha peningkatan kebahagiaan hidup mereka. Bagi organisasi, penelitian tentang kepuasan kerja dilakukan dalam rangka usaha meningkatkan produktivitas dan pengurangan biaya operasional melalui perbaikan perilaku dan sikap karyawannya. Selanjutnya, masyarakat tentu akan menikmati hasilnya dari pencapaian kapasitas maksimum industri dan meningkatnya penghargaan nilai manusia di perusahaan. Sedangkan ketidakpuasan merupakan titik awal dari masalah kemangkiran, konflik pimpinan dan karyawan, turn over yang tinggi, dan lain 
sebagainya. Bila dilihat dari sisi pekerja atau pegawai, ketidakpuasan berdampak pada menurunnya motivasi kerja, menurunnya moral kerja, menurunya loyalitas, dan akhirnya sampai pada menurunnya keterampilan kerja baik secara kualitas maupun kuantitas.

SDM sebagai unsur yang berperan penting dalam kegiatan organisasi diharapkan dapat mewujudkan visi dan misi organisasi. Maka SDM harus dikelola dengan baik sehingga berdaya guna dalam mencapai misi dan tujuan organisasi. Untuk mencapai tujuan organisasi maka diperlukan pegawai yang mampu menjalankan tugas-tugas yang telah ditentukan oleh organisasi. Setiap organisasi atau instansi pemerintah selalu berusaha untuk meningkatkan kinerja karyawannya, dengan harapan apa yang menjadi tujuan organisasi dapat tercapai. Kemampuan pegawai tercermin dari kinerja, kinerja yang baik adalah kinerja yang optimal. Kinerja pegawai merupakan salah satu modal bagi organisasi untuk mencapai tujuan. Kinerja pegawai menurut Sedarmayanti (2016:260) yaitu hasil kerja yang dicapai seseorang dalam melaksanakan tugas-tugas yang dibebankan kepadanya untuk mencapai target kerja.

Menurut Robbins (2010:75), faktor-faktor yang digunakan untuk meningkatkan kinerja pegawai diantaranya motivasi dan kepuasan kerja. Kepuasan kerja pada dasarnya merupakan hal yang bersifat individual, setiap individual memiliki tingkat kepuasan kerja yang berbeda-beda sesuai dengan keinginan dan sistem nilai yang dianutnya. Semakin banyak aspek dalam pekerjaannya yang sesuai dengan keinginan dan sistem yang dianutnya, maka semakin tinggi tingkat kepuasan kerja yang didapat.

Kepuasan kerja mencerminkan keadaan perasaan seseorang terhadap pekerjaan dan segala sesuatu di lingkungan pekerjaannya (Hasibuan, 2015:202). Kepuasan kerja merupakan aktualisasi diri pegawai dalam pekerjaannya. Pegawai di Bidang Program dan Perencanaan Umum Balai Besar Wilayah Sungai Mesuji Sekampung yang mendapatkan kepuasan kerja yang baik dapat dilihat dari gaji pegawai, insentif atau tunjangan yang diterima, perputaran kerja pegawai, dan prestasi kerja pegawai yang baik dibandingkan pegawai yang tidak mendapatkan kepuasan kerja. Kepuasan kerja dapat memberikan manfaat bagi pegawai maupun organisasi tersebut. Bagi pegawai diteliti tentang sebab dan sumber kepuasan kerja serta usaha yang dapat meningkatkan kepuasan kerja pegawai. Sedangkan bagi organisasi penelitian dilakukan untuk tercapainya tujuan organisasi.

Berikut di bawah ini gambar 1.1 yang menggambarkan tingkat kepuasan insentif yang diterima oleh pegawai di Bidang Program dan Perencanaan Umum Balai Besar Wilayah Sungai Mesuji Sekampung :

Gambar 1.1.

Kepuasan insentif yang diterima pegawai

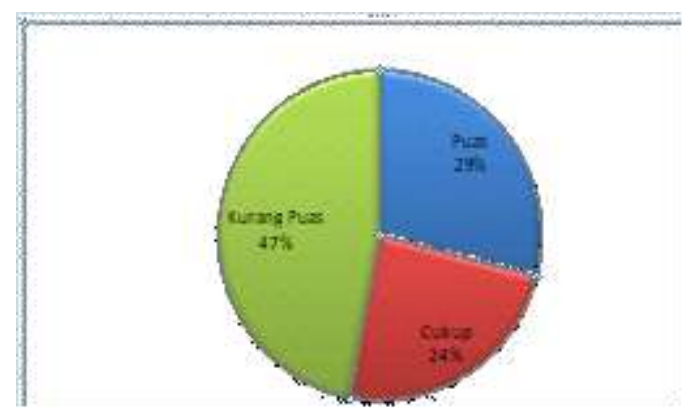

Sumber: Bidang Program dan Perencanaan Umum Balai Besar Wilayah Sungai Mesuji Sekampung, 
Dari gambar 1.1 di atas terlihat bahwa insentif yang diterima pegawai sebanyak $47 \%$ merasa kurang puas, $29 \%$ merasakan puas, sedangkan sisanya sebanyak $24 \%$ merasa cukup sehingga hal ini butuh penelitian lebih lanjut. Berikut di bawah ini gambar 1.2 yang menunjukkan hasil pekerjaan pegawai di Bidang Program dan Perencanaan Umum Balai Besar Wilayah Sungai Mesuji Sekampung.

\section{Gambar 1.2}

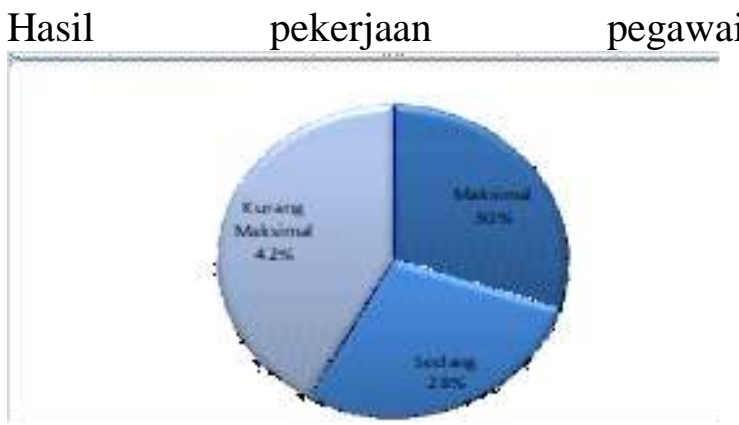

Sumber: Bidang Program dan Perencanaan Umum Balai Besar Wilayah

Dari gambar 1.2 di atas terlihat bahwa hasil pekerjaan yang dilaksanakan oleh pegawai di Bidang Program dan Perencanaan Umum Balai Besar Wilayah Sungai Mesuji Sekampung tidak seluruhnya berjalan dengan baik dan maksimal, hal ini butuh penelitian lebih lanjut.

Tentunya pada Bidang Program dan Perencanaan Umum Balai Besar Wilayah Sungai Mesuji Sekampung dalam mempertahankan kelangsungan organisasi dalam menghadapi iklim kompetisi yang dihadapi akan sangat berbeda. Hal ini membuat Bidang Program dan Perencanaan Umum Balai Besar Wilayah Sungai Mesuji Sekampung dapat bekerja lebih efisien, efektif dan produktif dengan memberikan perhatian pada aspek SDM nya. Dalam hal ini dengan memberikan kesempatan seleksi karir untuk jenjang yang lebih tinggi, memberikan reward untuk pegawai yang berprestasi, pemberian insentif yang sesuai dan wajar.
Berdasarkan uraian tersebut di atas, penulis bermaksud untuk meneliti kepuasan kerja dan kinerja pegawai guna peningkatan hasil kerja dalam kinerja yang dituangkan ke dalam proposal penelitian dengan judul "Pengaruh Kepuasan Kerja Terhadap Kinerja Pegawai di Bidang Program dan Perencanaan Umum Balai Besar Wilayah Sungai Mesuji Sekampung di Bandar Lampung."

\section{METODE PENELITIAN}

Penelitian ini dilakukan di kantor Bidang Program dan Perencanaan Umum Balai Besar Wilayah Sungai Mesuji Sekampung, yang beralamatkan di Jl. Gatot Subroto No. 50 Garuntang, Bandar Lampung. Penelitian ini dilakukan pada bulan April - Juni 2020 di Kantor Bidang Program dan Perencanaan Umum Balai Besar Wilayah Sungai Mesuji Sekampung, dengan obyek penelitian pegawai balai.

Dalam penelitian ini jenis data yang diperlakukan adalah :

\section{Data Primer}

Data primer dalam hal ini merupakan data yang diperoleh langsung tanpa perantara orang atau lembaga lain sebagai pihak ketiga. Data primer ini diperoleh dengan wawancara melalui responden dengan menggunakan daftar pertanyaan.

Data Sekunder

Merupakan data yang diperoleh melalui orang lain yang berhubungan dengan permasalahan yang dipecahkan. Data sekunder ini diperoleh melalui cara studi dokumenter yaitu mengumpulkan dan mempelajari brosur-brosur serta dokumen organisasi.

Pengumpulkan data yang sesuai dengan kebutuhan dalam penelitian ini maka teknik-teknik yang digunakan adalah sebagai berikut : Observasi, wawancara, kuisioner, dokumentasi 
Untuk menentukan populasi dan sampel Arikunto (2012:14) menyatakan ukuran minimum sampel untuk keperluan penelitian ini lebih dari 100 orang diambil sebanyak $25 \%$ dari jumlah keseluruhan populasi. Untuk keperluan penelitian ini maka sampel diambil dari jumlah populasi pegawai Bidang Program dan Perencanaan Umum Balai Besar Wilayah Sungai Mesuji Sekampung. Populasi yang akan diteliti oleh penulis adalah responden yang berupa pegawai Bidang Program dan Perencanaan Umum Balai Besar Wilayah Sungai Mesuji Sekampung secara kolektif dengan pengisian kuesioner atau observasi, yaitu dengan mengambil sampel berdasarkan kegiatan dalam kondisi normal dan mau memberikan jawaban pada angket yang diberikan. Dalam penelitian ini teknik sampel jenuh digunakan sebab jumlah populasi berjumlah 50 orang.

Sebelum alat analisis digunakan, terlebih dahulu dilakukan ujicoba terhadap alat ukur dengan tujuan untuk mengetahui reliabilitas terhadap kuesioner yang akan digunakan, sehingga hasil pengukuran yang akan diperoleh nantinya dapat dipertanggung jawabkan. Untuk itu uji reliabilitas digunakan sebagai alat ukur dengan teknik Alpha Cronbach melalui program statistika pada. Pedoman yang digunakan untuk rentang besarnya koefisien $\alpha$ pada teknik Alpha Chronbach adalah sebagai berikut: George (2013)

$$
\begin{array}{ll}
\alpha>0,9 & =\text { excellent } \\
0,8<\alpha \leq 0,9 & =\text { good } \\
0,7<\alpha \leq 0,8 & =\text { acceptable } \\
0,6<\alpha \leq 0,7 & =\text { questionable } \\
0,5<\alpha \leq 0,6 & =\text { poor } \\
\alpha \leq 0,5 & =\text { unacceptable }
\end{array}
$$

Analisis Kuantitatif
Yaitu suatu analisis dengan menggunakan data yang ada, kemudian menguraikan hasil penelitian dalam bentuk angka-angka melalui uji statistik yang tepat dan relevan. Hal ini dimaksudkan agar memudahkan dalam pengolahannya dan teruji kebenarannya, karena data berupa angka maka akan lebih mudah pula dalam penarikan kesimpulan.

Berikut di bawah ini ada beberapa rumus yang digunakan dalam menganalisis data guna mengetahui ada atau tidaknya pengaruh antara Kepuasan Kerja (variabel $\mathrm{X}$ ) dengan Kinerja (variabel Y) :

Uji regresi linier sederhana, rumusnya :

$\mathrm{Y}=\mathrm{a}+\mathrm{bX}$

Keterangan :

$$
\begin{aligned}
\mathrm{Y} & =\text { Kinerja } \\
\mathrm{a} & =\text { konstanta } \\
\mathrm{b} & =\text { koefisien regresi (besaran) } \\
\mathrm{X} & =\text { Kepuasan Kerja }
\end{aligned}
$$

Nilai a dan $b$ dapat dihitung dengan rumus dibawah ini :

\section{Uji Hipotesis (Uji T)}

Sedangkan untuk menguji hipotesisnya penulis menggunakan uji $\mathrm{T}$ ( $\mathrm{T}$ test) sebagaimana yang dikemukakan Arikunto (2012) dengan rumus sebagai berikut:

$$
\mathrm{T}=\mathrm{R} \quad \mathrm{n}-2
$$

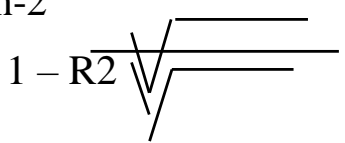

\section{Keterangan:}

$$
\begin{array}{ll}
\mathrm{T} & =\text { penguji koefisien korelasi } \\
\mathrm{R} & =\text { koefisien korelasi }
\end{array}
$$


$\mathrm{n} \quad=$ jumlah sampel

Perhitungan di atas menggunakan derajat kebebasan $=n-2$, dengan ketentuanketentuan sebagai berikut:

Apabila t-hitung > t-tabel, maka Ha diterima Ho ditolak

Apabila t-hitung < t-tabel, maka Ha ditolah Ho diterima

\section{HASIL DAN PEMBAHASAN}

Hasil Penelitian

Kantor Balai Besar Wilayah Sungai Mesuji Sekampung beralamat di Jln. Gatot Subroto No. 50 Garuntang, Bandar Lampung. Balai Besar Wilayah Sungai Mesuji Sekampung (BBWS MS) merupakan salah satu Balai yang dibentuk berdasarkan Peraturan Menteri Pekerjaan Umum Nomor : 13/PRT/M/2006 tanggal 17 Juli 2006 tentang Organisasi dan Tata Laksana Balai Wilayah Sungai yang kemudian dirubah dengan Peraturan Menteri Pekerjaan Umum Nomor: 26/PRT/M/2006 tanggal 9 November 2006 tentang Perubahan atas Peraturan Menteri Nomor 12/PRT/M/2006 Tentang Susunan Organisasi dan Tata Laksana Balai Besar Wilayah Sungai dan Peraturan Menteri Pekerjaan Umum Nomor : 13/PRT/M/2006 tentang Susunan Organisasi dan Tata Laksana Balai Wilayah Sungai.

Terbentuknya Balai Besar Wilayah Sungai Mesuji Sekampung merupakan kesinambungan program beberapa Satuan Kerja. Sebelum berdirinya Balai Besar Wilayah Sungai Mesuji Sekampung (sebagaimana diamanatkan Undang Undang Nomor 7 Tahun 2004 tentang Sumber Daya Air), Departemen Pekerjaan Umum khususnya Direktorat Jenderal Sumber Daya Air (dahulu Direktorat Jenderal Pengairan) memiliki satuan kerja yang berfungsi melaksanakan pekerjaan baik konstruksi maupun non konstruksi di masing-masing provinsi.

Khusus di Provinsi Lampung satuan kerja yang mengelola bidang sumber daya air terdiri dari beberapa Satuan Kerja Non Vertikal Tertentu (SNVT) antara lain SNVT Irigasi dan Rawa Andalan Lampung, SNVT Pengelolaan Air Baku, SNVT. Induk Pelaksana Kegiatan Pengembangan Wilayah Sungai WS Seputih WS Sekampung yang Membawahi SNVT Pengembangan dan Konservasi Sumber Air, SNVT Pengendalian Banjir dan Pengamanan Pantai serta SNVT Banjir Way Seputih Way Sekampung. Masing-masing SNVT tersebut berkoordinasi dengan direktorat terkait di lingkungan Direktorat Jenderal Sumber Daya Air, Departemen Pekerjaan Umum sesuai bidang yang dikelola.

Sebagaimana diamanatkan dalam UU Nomor 7 Tahun 2004 tentang Sumber Daya Air, Menteri Pekerjaan Umum melalui Peraturan Menteri PU Nomor 11a/PRT/M/2006 tanggal 28 Juni 2006 telah menetapkan pengelolaan sungai di Indonesia yang dibagi dalam 133 Wilayah Sungai (WS). Dari jumlah tersebut, yang merupakan kewenangan pemerintah (pusat) sejumlah 69 WS yang terdiri dari 5 WS lintas negara, 27 WS lintas provinsi dan 37 WS strategis Nasional. Berdasarkan Peraturan Menteri PU tersebut, BBWS Mesuji Sekampung mengelola 2 Wilayah Sungai di Provinsi Lampung yaitu Wilayah Sungai Seputih Sekampung dan Wilayah Sungai Mesuji Tulang Bawang, yang sebelumnya dikelola oleh Satuan Kerja Non Vertikal Tertentu (SNVT) yang ada di Provinsi Lampung.

Berdasarkan Permen. PU No. 12 /PRT/M/2006 BBWS Mesuji Sekampung dibentuk untuk mengelola :

Wilayah Sungai Seputih Sekampung

Wilayah Sungai Seputih Sekampung sebagai Wilayah Sungai Strategis Nasional. Wilayah Sungai Seputih Sekampung meliputi 
beberapa wilayah kabupaten/kota yaitu : Kabupaten Lampung Barat. Kabupaten Tanggamus, Kabupaten Lampung Tengah, Kabupaten Pesawaran, Kota Bandar Lampung, Kota Metro, Kabupaten Lampung Timur, Kabupaten Lampung Selatan, Kabupaten Tulang Bawang.

Wilayah Sungai Mesuji Tulang Bawang sebagai Wilayah Sungai Lintas Provinsi.

Wilayah Sungai Mesuji Tulang Bawang meliputi beberapa kabupaten, yaitu Kabupaten Lampung Barat, Kabupaten Way Kanan, Kabupaten Lampung Utara, Kabupaten Lampung Tengah, Kabupaten Tulang Bawang, Kabupaten Mesuji, dan sebagian kabupaten di Provinsi Sumatera Selatan.

\section{Pembahasan}

Sebelum melakukan penelitian dengan dasar metode penelitian yang disusun pada Bab III maka angket penelitian diujikan terlebih dahulu. Dari hasil uji coba angket pada responden setara terhadap variabel-variabel yang akan diteliti kepada 25 responden setara, diperoleh hasil sebagai berikut:

a. Hasil Uji Validitas Butir Pernyataan Variabel X

Tabel 4.1 Uji Validitas Butir Pertanyaan Variabel X

\begin{tabular}{|c|c|c|c|c|c|c|c|c|}
\hline \multicolumn{9}{|c|}{ Correlations } \\
\hline & & $x 1$ & $\times 2$ & $x^{3}$ & $x 4$ & $\times 5$ & $\times 6$ & $x$ \\
\hline \multirow[t]{3}{*}{$x 1$} & Pearson Correlation & 1 & $605^{\prime \prime}$ &, $505^{* \prime}$ & $605^{\prime \prime}$ &, $505^{* \prime}$ &, $618^{\prime \prime}$ &, $748^{* \prime \prime}$ \\
\hline & Sig. (2-tailed) & & , 001 & ,010 & . 001 & , 010 & , 001 &, 000 \\
\hline & $\mathrm{N}$ & 25 & 25 & 25 & 25 & 25 & 25 & 25 \\
\hline \multirow[t]{3}{*}{$\times 2$} & Pearson Correlation & ,605" & 1 & $495^{*}$ & $1,000^{\prime \prime}$ & $.495^{*}$ & ,525" & $801^{* *}$ \\
\hline & Sig. (2-tailed) &, 001 & &, 012 &, 000 &, 012 & ,007 &, 000 \\
\hline & N & 25 & 25 & 25 & 25 & 25 & 25 & 25 \\
\hline \multirow[t]{3}{*}{$x 3$} & Pearson Correlation &, $505^{*}$ &, $495^{\circ}$ & 1 & $495^{*}$ & $1,000^{* *}$ & $873^{\prime \prime}$ & $890^{*+*}$ \\
\hline & Sig. (2-tailed) &, 010 &, 012 & & ,012 &, 000 &, 000 &, 000 \\
\hline & $\mathrm{N}$ & 25 & 25 & 25 & 25 & 25 & 25 & 25 \\
\hline \multirow[t]{3}{*}{$x 4$} & Pearson Correlation & $605^{* \prime}$ & $1,000^{*}$ & $495^{*}$ & 1 & $.495^{*}$ &, $525^{*}$ & $801^{*+}$ \\
\hline & Sig. (2-tailed) & ,001 &, 000 &, 012 & &, 012 & ,007 &, 000 \\
\hline & $\mathrm{N}$ & 25 & 25 & 25 & 25 & 25 & 25 & 25 \\
\hline \multirow[t]{3}{*}{$\times 5$} & Pearson Correlation &, $505^{* \prime}$ & $495^{\circ}$ & $1,000^{* \prime}$ & $495^{\circ}$ & 1 &, $873^{\prime \prime}$ & $890^{*+}$ \\
\hline & Sig. (2-tailed) &, 010 & 012 &, 000 & 012 & &, 000 &, 000 \\
\hline & $\mathrm{N}$ & 25 & 25 & 25 & 25 & 25 & 25 & 25 \\
\hline \multirow[t]{3}{*}{$\times 6$} & Pearson Correlation & ,618" &, $525^{* \prime}$ &, $873^{\prime \prime \prime}$ & $525^{\prime \prime}$ &, $873^{\prime \prime \prime}$ & 1 & , $888^{\prime \prime \prime}$ \\
\hline & Sig. (2-tailed) &, 001 & ,007 &, 000 & ,007 &, 000 & &, 000 \\
\hline & $\mathrm{N}$ & 25 & 25 & 25 & 25 & 25 & 25 & 25 \\
\hline \multirow[t]{3}{*}{$x$} & Pearson Correlation & ,748" & $801^{* *}$ & $890^{\circ *}$ & $801^{\prime \prime}$ & $890^{* *}$ & $888^{\prime \prime}$ & 1 \\
\hline & Sig. (2-tailed) &, 000 &, 000 &, 000 &, 000 &, 000 &, 000 & \\
\hline & $\mathrm{N}$ & 25 & 25 & 25 & 25 & 25 & 25 & 25 \\
\hline
\end{tabular}

${ }^{*}$. Correlation is significant at the 0.01 level (2-tailed).

*. Correlation is significant at the 0.05 level (2-tailed).

\section{Reliability Statistics}

\begin{tabular}{|r|r|}
\hline $\begin{array}{c}\text { Cronbach's } \\
\text { Alpha }\end{array}$ & N of Items \\
\hline, 914 & 6 \\
\hline
\end{tabular}

Sumber: Data Primer Hasil Uji coba (SPSS)

b. Hasil Uji Validitas Butir Pertanyaan Variabel Y

Tabel 4.2 Uji Validitas Butir Pertanyaan Variabel Y 


\begin{tabular}{|c|c|c|c|c|c|c|c|c|}
\hline \multicolumn{9}{|c|}{ Correlations } \\
\hline & & $y 1$ & 12 & $y_{3}$ & $y 4$ & $y 5$ & 16 & $y$ \\
\hline \multirow[t]{3}{*}{$\overline{y 1}$} & Pearson Correlation & 1 &, 370 & 328 & $.456^{*}$ & $1,000^{\prime \prime}$ & ,328 & $.655^{\prime \prime}$ \\
\hline & Sig. (2-tailed) & & ,069 &, 110 &, 022 &, 000 & ,110 &, 000 \\
\hline & $\mathrm{N}$ & 25 & 25 & 25 & 25 & 25 & 25 & 25 \\
\hline \multirow[t]{3}{*}{12} & Pearson Correlation & 370 & 1 & ,578" & ,646" &, 370 & ,578" & $.814^{4}$ \\
\hline & Sig. (2-tailed) & , 069 & & ,002 & ,000 &, 069 & , 002 & ,000 \\
\hline & $\mathrm{N}$ & 25 & 25 & 25 & 25 & 25 & 25 & 25 \\
\hline \multirow[t]{3}{*}{$\beta$} & Pearson Correlation &, 328 &, $578^{\prime \prime}$ & 1 &, $798^{\prime \prime}$ &, 328 & $1,000^{\prime \prime}$ & $.854^{\prime \prime}$ \\
\hline & Sig. (2-tailed) & 110 & , 002 & & , & 110 & ,000 & ,000 \\
\hline & $\mathrm{N}$ & 25 & 25 & 25 & 25 & 25 & 25 & 25 \\
\hline \multirow[t]{3}{*}{$y 4$} & Pearson Correlation &, $456^{\circ}$ &, $646^{*}$ &, $798^{\prime \prime}$ & 1 & $.456^{*}$ &, $798^{\prime \prime}$ & $.892^{\prime \prime}$ \\
\hline & Sig. (2-tailed) & , 022 & . & , 000 & & ,022 & , 000 & ,000 \\
\hline & $\mathrm{N}$ & 25 & 25 & 25 & 25 & 25 & 25 & 25 \\
\hline \multirow[t]{3}{*}{ y5 } & Pearson Correlation & $1,000^{\prime \prime}$ & 370 & 328 &, $456^{\circ}$ & 1 & 328 & $.655^{\prime \prime}$ \\
\hline & Sig. (2-tailed) & ,000 &, 069 & , 110 &, 022 & & ,110 &, 000 \\
\hline & N & 25 & 25 & 25 & 25 & 25 & 25 & 25 \\
\hline \multirow[t]{3}{*}{16} & Pearson Correlation & ,328 &, $578^{\prime \prime}$ & $1,000^{\prime \prime}$ & ,798" &, 328 & 1 & $.854^{\prime \prime}$ \\
\hline & Sig. (2-tailed) & 110 & , 002 & ,000 & ,000 & 110 & & ,000 \\
\hline & $\mathrm{N}$ & 25 & 25 & 25 & 25 & 25 & 25 & 25 \\
\hline \multirow[t]{3}{*}{ y } & Pearson Correlation & $655^{\prime \prime}$ &, $814^{\prime \prime}$ & $854^{\prime \prime}$ & ,892" & $6,655^{\prime \prime}$ & $854^{\prime \prime}$ & 1 \\
\hline & Sig. (2-tailed) & , 000 & , 000 &, 000 &, 000 &, 000 &, 000 & \\
\hline & $\mathrm{N}$ & 25 & 25 & 25 & 25 & 25 & 25 & 25 \\
\hline
\end{tabular}

*. Correlation is significant at the 0.05 level (2-tailed).

**. Correlation is significant at the 0.01 level (2-tailed).

\section{Reliability Statistics}

\begin{tabular}{|r|r|}
\hline $\begin{array}{c}\text { Cronbach's } \\
\text { Alpha }\end{array}$ & N of Items \\
\hline, 879 & 6 \\
\hline
\end{tabular}

Sumber: Data Primer Hasil Uji coba (SPSS)

Dari hasil pengujian tabel di atas, menunjukan validitas (corrected item-total correlation) koefisien korelasi item pada variabel $\mathrm{X}$ dan $\mathrm{Y}$ seluruhnya valid. Hasil analisis uji reliabilitas yang terjadi menunjukkan bahwa kuesioner reliable, karena skor alpha positif dengan nilai 0.914 untuk alpha $\mathrm{X}$ dan 0.879 untuk alpha $\mathrm{Y}$ dan lebih besar dari 0.6 (Arikunto, 2012). Dengan demikian dapat dikatakan kuesioner variabel $\mathrm{X}$ dan $\mathrm{Y}$ layak untuk digunakan dalam pengambilan data penelitian.

\section{Analisis Data}

Guna memudahkan dan pencapaian target analisis yang akurat, maka dalam operasional analisis data digunakan program statistika pengolahan data dalam penelitian ini responden berjumlah 50 responden, yang dapat digunakan dalam keadaan baik. Sebelum dilakukan pengolahan data dilakukan uji terhadap asumsi klasik untuk menghindari asumsi klasik yaitu uji normalitas, dan uji homogenitas.

Uji Normalitas

Dengan menggunakan program SPSS, hasil uji normalitas yang dilakukan dapat dilihat dengan hasil grafik normalitas, yang ditampilkan sebagai berikut:

Gambar 4.1 Grafik Normalitas

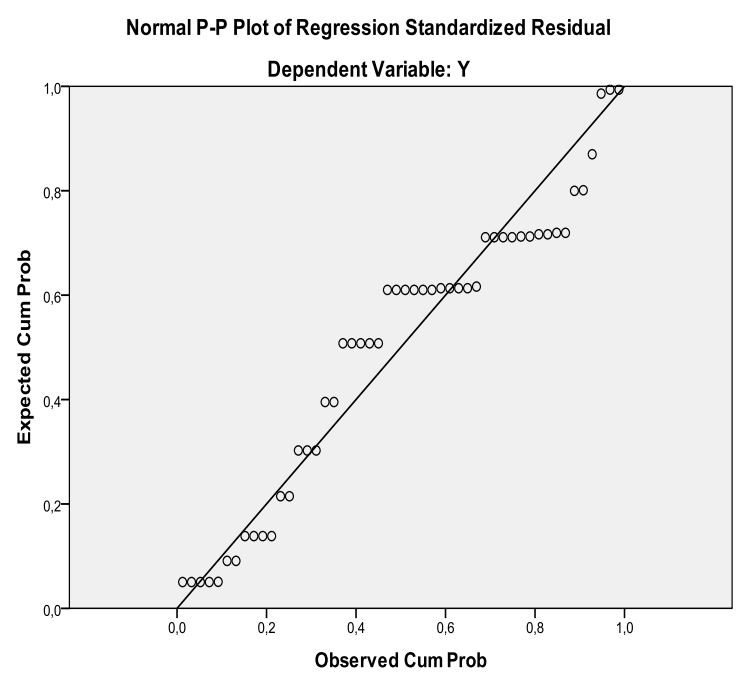

Sumber data : Grafik SPSS

Pola penyebaran yang terjadi berada pada sekitar garis diagonal dan mengikuti garis diagonal tersebut berisifat moderate tetapi masih disekitaran sumbu normal. Ini berarti bahwa model regresi dalam penelitian ini sudah memenuhi asumsi normalitas dengan nilai moderate, yaitu variabel - variabel yang digunakan dalam penelitian ini mempunyai distribusi yang normal.

Uji Homogenitas

Untuk menguji homogenitas digunakan metode visual berdasarkan hasil olahan data dengan program SPSS yaitu dengan cara melihat penyebaran nilai-nilai residual terhadap nilai prediksi.sebagai berikut : 


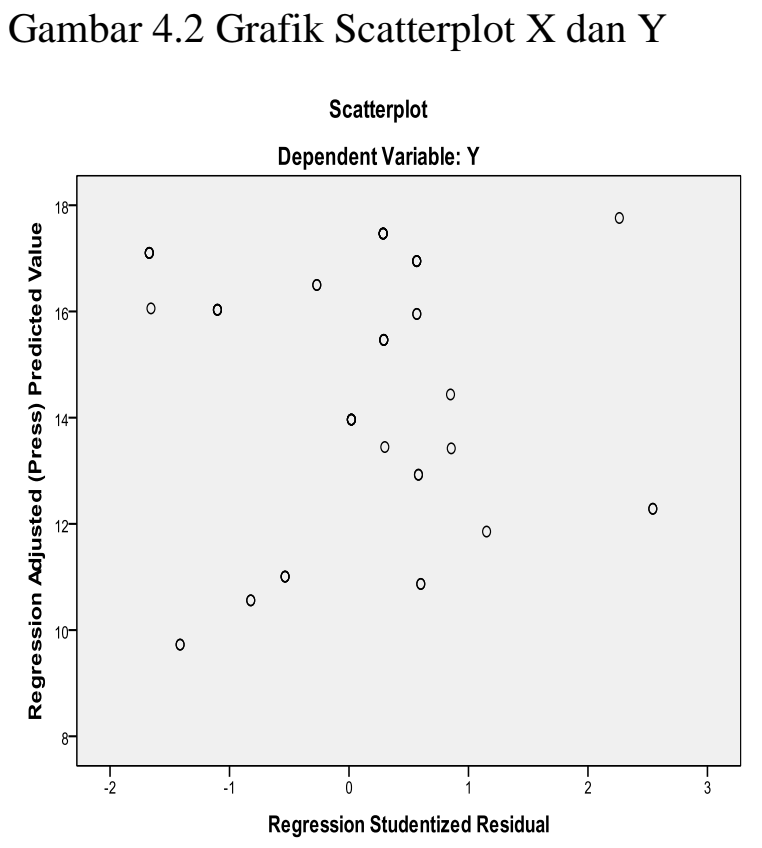

Sumber : Hasil Olah Data SPSS

Berdasarkan seluruh gambar grafik di atas, diketahui bahwa penyebaran nilai - nilai perbandingan tersebut tidak membentuk pola tertentu sehingga keadaan homogenitas dapat terpenuhi pada homogenitas Variabel X1 dan Variabel Y. Maka berdasarkan hasil uji data Normalitas dan Homogentitas data penelitian dapat dilanjutkan ke uji selanjutnya yaitu regresi.

Hasil Penelitian

Setelah uji Normalitas dan Homogenitas terpenuhi maka data siap untuk dilakukan dengan pembuktian hipotesis penelitian. Hasil uji regresi linear yang dilakukan dengan menggunakan program statistika (SPSS) dengan acuan hasil perhitungan analisis statistik data dijelaskan sebagai berikut:

Model persamaan regresi untuk fungsi ini adalah :

$$
\mathrm{Y}=\mathrm{a}+\mathrm{bX}
$$

Dimana

$\begin{array}{lll}\mathrm{Y} & = & \text { kinerja } \\ \mathrm{X} & = & \text { kepuasan kerja }\end{array}$

$$
\begin{array}{lll}
\mathrm{a} & = & \text { konstanta } \\
\mathrm{b} & = & \text { koefisien regresi }
\end{array}
$$

Acuan hasil tersebut dapat digunakan sebagai panduan dalam mengartikan hasil dari pengolahan data dengan menggunakan program SPSS. Hasil diperoleh model regresi linier dengan Pembuktian Hipotesis "diduga ada Pengaruh Kepuasan Terhadap Kinerja Pegawai di Bidang Program dan Perencanaan Umum Balai Besar Wilayah Sungai Mesuji Sekampung di Bandar Lampung". Berdasarkan hasil analisis data maka hasil analisis yang didapatkan adalah sebagai berikut:

Tabel 4.3 Hasil Analisis Hipotesis

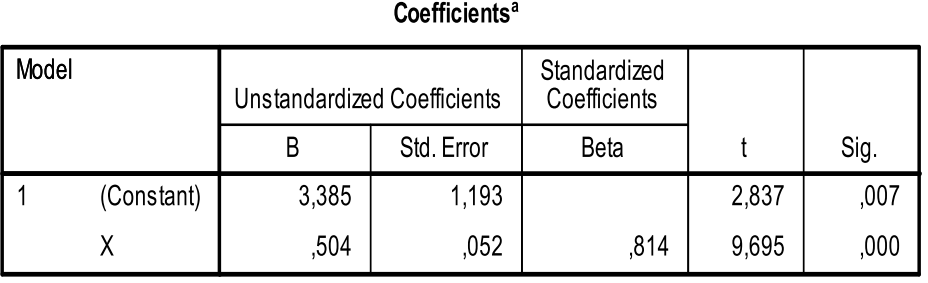

a. Dependent Variable: $Y$

\section{Model Summary}

\begin{tabular}{|l|l|r|r|r|}
\hline Model & $\mathrm{R}$ & R Square & \multicolumn{1}{|c|}{$\begin{array}{c}\text { Adjusted } \mathrm{R} \\
\text { Square }\end{array}$} & $\begin{array}{c}\text { Std. Error of } \\
\text { the Estimate }\end{array}$ \\
\hline 1 &, $814^{\mathrm{a}}$ &, 662 &, 655 & 1,82110 \\
\hline
\end{tabular}

a. Predictors: (Constant), $X$

b. Dependent Variable: $Y$

\section{Sumber: Hasil Oleh Data SPSS}

Berdasarkan hasil uji tersebut maka didapatkan persamaan model regresi yang sebagai berikut :

$\mathrm{Y}$

t hitung

$(9,695)$

$$
\begin{array}{ll}
\mathrm{R} 2 & =0.662 \\
\mathrm{~N} & =50
\end{array}
$$

Dari hasil regresi yang telah didapat, maka dapat hasil penelitian dapat diinterpretasikan 
pada Uji t yang dilakukan untuk melihat besarnya pengaruh secara individu variabel bebas terhadap variabel tak bebas. Dan hasil estimasi dapat kita lihat bahwa nilai t hitung untuk variabel (X) sebesar 9,695 (Prob.sig. $=0,000)$ yang berarti $t$ hitung $>\mathrm{t}$ tabel dengan tingkat signifikansi 95\% (persen). Kemudian koefisien determinasi (R2) memiliki nilai yang sedang yaitu sebesar 0,662 yang berarti $66,2 \%$ memiliki pengaruh sedang pada kepuasan kerja terhadap kinerja. Setelah dilakukan pembuktian hipotesis, selanjutnya dilakukan analisis untuk menguji kaitan butir terhadap variabel dan dilakukan pada setiap variabel uji guna mendapatkan hasil kontribusi butir yang lebih detail pada setiap variabel dengan menggunakan perthitungan rata - rata jawaban, Arikunto (2012). Berikut ditampilkan hasil uji rata - rata butir terhadap variabel uji yang ditampilkan dalam tabel sebagai berikut:

Tabel 4.4 Hasil Analisis Rata Rata Jawaban Butir Pada Konsep

\begin{tabular}{|c|c|c|c|c|c|c|}
\hline Variabel & \multicolumn{6}{|c|}{ No Quesioner pada Angket } \\
\hline Item & 1 & 2 & 3 & 4 & 5 & 6 \\
\hline Kepuasan Kerja & 3.05 & 3.63 & 4.13 & 3.63 & 4.13 & 4.4 \\
\hline Variabel & \multicolumn{7}{|c|}{ No Quesioner pada Angket } \\
\hline Item & 1 & 2 & 3 & 4 & 5 & 6 \\
\hline Kinerja & 3,07 & 3.70 & 3.83 & 4.23 & 3.05 & 3.7 \\
\hline
\end{tabular}

Sumber: Hasil Oleh Data SPSS

Berdasarkan hasil uji tersebut diketahui bahwa butir dengan rata - rata yang paling kecil pada variabel Kepuasan kerja adalah butir X1. Kemudian pada Variabel kinerja adalah butir Y5. Guna memudahkan interpretasi dari hasil regresi linier sederhana yang digabungkan dengan kontribusi pada butir terhadap variabel ujinya pada variabel - variabel yang mempengaruhi maka hasil analisis dirangkum dan dapat diinterpretasikan bahwa kepuasan kerja memiliki pengaruh yang sedang yaitu sebesar 66,2\% terhadap kinerja pada Pegawai Kegiatan Ketatalaksanaan di
Kantor Balai Besar Wilayah Sungai Mesuji Sekampung di Bandar Lampung. Pada variabel Kepuasan kerja juga didapatkan yaitu bahwa butir Anda dapat bekerja dengan team kerja dengan baik, memiliki kontribusi yang paling kecil. Kemudian pada variabel Kinerja butir yang paling kecil adalah Tidak menunda pekerjaan yang telah diberikan pimpinan.

\section{KESIMPULAN}

Berdasarkan bahwa nilai $\mathrm{t}$ hitung untuk variabel (X1) sebesar 9,695 (Prob.sig. = $0,000)$ yang berarti thitung $>\mathrm{t}$ tabel dengan tingkat signifikansi 95\% (persen). Hal ini menunjukkan bahwa koefisien masing variabel bebas adalah penting secara statistik pengaruhnya terhadap variabel tak bebasnya atau dengan kata lain bahwa berpengaruh Signifikan. Kemudian koefisien determinasi (R2) memiliki nilai yang sedang yaitu sebesar 0,662 yang berarti $66,2 \%$ memiliki pengaruh sedang pada kepuasan kerja terhadap kinerja. Kesimpulan yang dapat ditarik adalah Kepuasan Kerja memiliki pengaruh yang sedang terhadap Kinerja Pegawai Kegiatan Ketatalaksanaan di Kantor Balai Besar Wilayah Sungai Mesuji Sekampung di Bandar Lampung.

\section{UCAPAN TERIMAKASIH}

Terimakasih kepada Universitas Sang Bumi Ruwa Jurai yang telah berkontribusi dalam penelitian ini

DAFTAR PUSTAKA

Amalia, Kartika. 2012. Pengaruh Kepuasan Kerja Terhadap Kinerja Karyawan Pada Agen PT. Jasaraharja Putera Cabang Jakarta. Fakultas Sosial dan Ilmu Politik Universitas Indonesia. 
Arikunto, Suharsimi, 2012. Prosedur Penelitian, Jakarta: PT. Rineka Cipta.

Buku Pedoman Penyusunan Skripsi dan Komprehensif Fakultas Ekonomi Universitas Sang Bumi Ruwa Jurai, 2019.

Gibson. 2015. Organization: Behaviour structure process, Jakarta: Bina Aksara.

Greenberg.2010. Behavior in Organizations. New Jersey: Pearson Education International

Handoko, T. Hani.2015. Manajemen Sumber Daya Manusia, Yogyakarta: Penerbit BPFE

Hasibuan, Malayu S.P., 2015. Manajemen Sumber Daya Manusia, Jakarta: Penerbit Bumi Aksara

Luthans. 2015. Perilaku Organisasi. Jakarta: Andi Publisher.

Makaluas, Christian. G. 2014. Pengaruh Kepuasan Kerja Terhadap Kinerja Karyawan PAda PT. BPR Prisma Dana Manado. Fakultas Ekonomi Universitas Sam Ratulangi.

Mangkunegara, Prabu. 2013. Manajemen

Sumber Daya Manusia

Perusahaan. cet. 2; Bandung: PT Remaja Rosdakarya.

Miftah. 2013. Perilaku Organisasi. Jakarta: Raja Grafindo

Rivai, V. (2011). Manajemen Sumber Daya Manusia untuk Perusahaan. Jakarta: PT. Raja Grafindo Persada.

Robbins. 2015. Perilaku Organisasi. Jakarta: Salemba Empat.
Sedarmayanti. 2016. Manajemen Sumber Daya Manusia. Bandung: PT. Refika Aditama.

Sinambela. 2012. Manajemen Sumber Daya Manusia. Jakarta: Bumi Aksara.

Siagian, Sondang P. 2011. Manajemen Sumber Daya Manusia, Jakarta: Penerbit Gramedia

Sinungan, Muchdarsyah, 2017, Manajemen Personalia, Jakarta: Penerbit Ghalia Indonesia

Siregar, S. (2013). Metode Penelitian Kuantitatif. Jakarta: Kencana

Syadam, Gauzali.2012. Manajemen Personalia Suatu Pendekatan Makro, Jakarta: Penerbit Djambatan.

Syaiin, Subakti. 2013. Pengaruh Kepuasan Kerja Terhadap Kinerja Pegawai Klinik Spesialis Bestari Medan. Fakultas Ekonomi Universitas Sumatera Utara.

Widjojo, Rosa. 2013. Pengaruh Kepuasan Kerja Terhadap Kinerja Karyawan PT. Semen Tonasa. Jurnal Modus, vol. 25, No. 3. 